\title{
Effect of Solar Radiation and Wind Speed on the Performance of Solar Dryer
}

\author{
Mu'azu Musa $^{1}$ and Mannir Ibrahim ${ }^{2}$ \\ ${ }^{1-2}$ Department of Mechanical Engineering \\ Faculty of Engineering and Environmental Design \\ Usmanu Danfodiyo University \\ Sokoto Nigeria
}

\begin{abstract}
This paper is to determine the effect of solar radiation and wind speed on the performance of solar dryers. The solar drying system uses solar radiation to dry agricultural products put on it. From the test carried out, it's revealed that the solar dryer can perform more efficiently in the drying system. The Indian standard method of testing solar thermal was adopted. From the result it was observed that the highest ambient temperature was 400C, the wind speed was $3.7 \mathrm{~m} / \mathrm{s}$ and the solar radiation was $944.1 \mathrm{~W} / \mathrm{m} 2$. For further research, candle wax should be used which can also fasten the rate of drying agricultural products and also investigate the performance of the solar dryers.
\end{abstract}

Keyword: Solar drying, Solar radiation, Solar performance.

\section{INTRODUCTION}

This trend increased as expected, reaching a global production of 508 million tons for vegetables Drying is one of the oldest methods using solar energy where products such as vegetables, fruits, fish, and meat are to be dried by exposing directly to the sun. It is a simple process of removing the moisture contents from a natural or industrial product in order to reach the standard specification. This method is economical on a large scale drying because of cheaper operating costs compared to the drying machine. However, this method has many disadvantages such as spoilt products due to rain, wind, dust, insect infestation, animal attack and fungi. Because of that, the solar dryer technology will become an alternative method which can process the products in clean, safe, hygienic and produce better quality and more nutritious foods. In general, this solar dryer has saved energy, labor intensive, time, less area for spreading the product to dry, makes the process more efficient and protects the environment [1].

\section{MATERIALS AND METHOD}

\subsection{Materials Used for the Solar Dryer Construction}

The following materials were used for the construction of a direct combine solar dryer:

- Galvanized Sheet: is used as the casing (housing) of some parts of the chamber (side and back of the drying chamber). A $0.9 \mathrm{~mm}$ thickness of the galvanized sheet was also used for the absorber plate.

- Glass - is used as the solar collector cover, the drying chamber and for the roofing. It Permits the solar radiation into the system but reduces the flow of heat energy out of the Systems

- Galvanized iron frames for the drying trays.

- Nails and glue as fasteners and adhesives.

- Insect net at air inlet and outlet - to prevent insects from entering into the dryer.

- Hinges and handle for the dryer's door.

- Paint (black) and top gum

- Pyranometer is used to measure solar radiation 
International Journal of Advances in Scientific Research and Engineering (ijasre), Vol 5 (10), October-2019

- Anemometer is used in measuring wind speed

- Weighing balance is used to weigh the weight of a substance

Also, a thermometer was used to measure the ambient and dryer temperature and wood is also used for the assembling of the entire dryer

\section{TOMATO SAMPLES}

In this study, tomato was chosen as the product to be dried because of its limited shelf life at ambient conditions and its high perishes ability. Good quality fruits were purchased from a local fruit market of Birnin kebbi. Tomatoes were washed with water to remove skin dirt, cut into slices of $1 \mathrm{~cm}$ thickness. Seeds were removed and the slices obtained were uniformly laid out on the trays of the direct solar dryer [2].

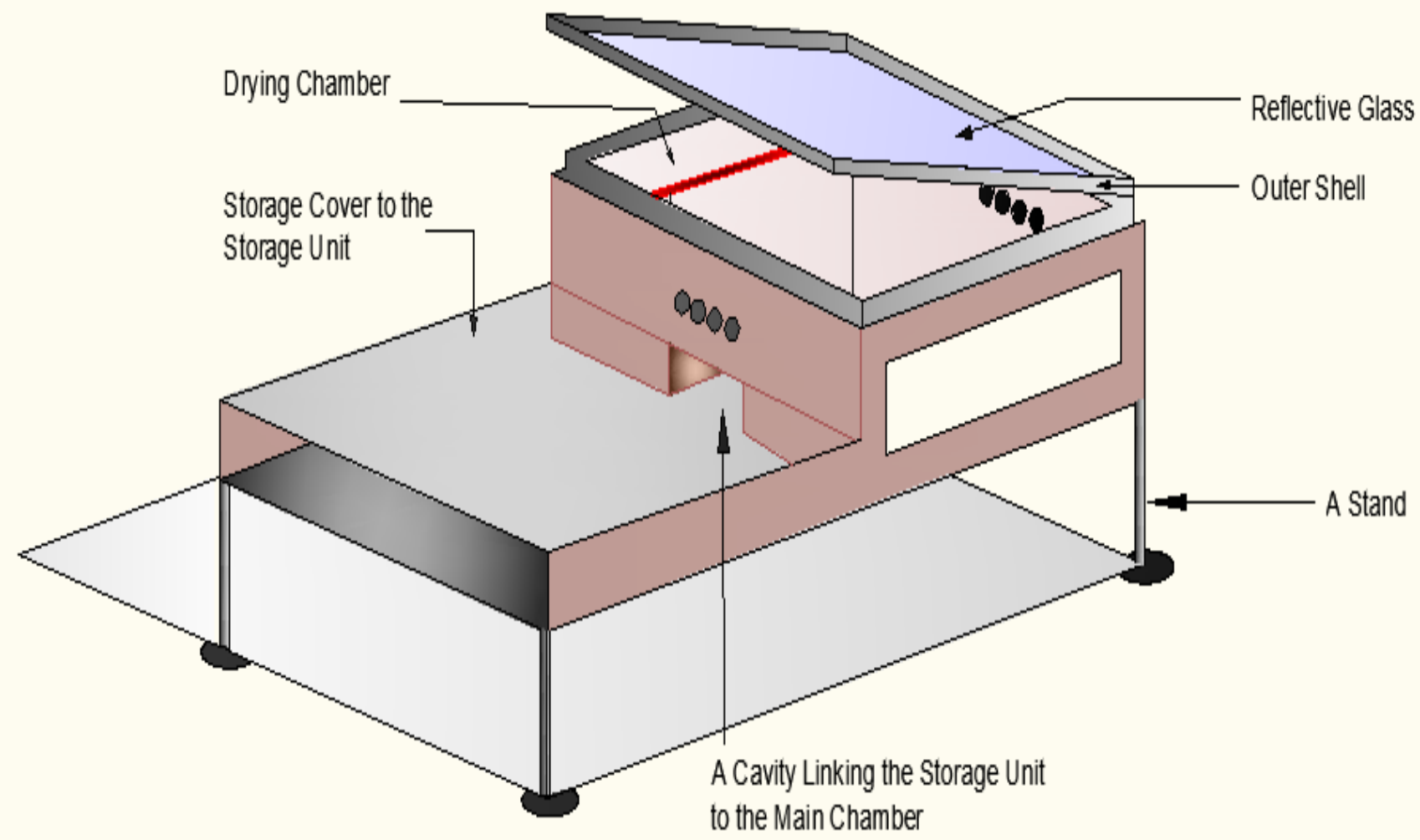

Figure: 1.0 showing the details of the solar dryer

\section{DATA COLLECTION}

The India standard based on thermal test for solar dryer, the method highlighted two methods of test firstly stagnation test (test without storage) and secondly the storage test [3]. The temperatures were measured by using thermometer and solar radiation was measured using pyranometer and also weighing balance was used to measure the weight of the tomatoes every one hour of the day. The wind speed is also measured by using the digital Anemometer, The test on solar dryer was done on the month of October 2017. As the experiment started around 8:00am and end 6:00pm, every 20 minutes data was collected and recorded further more average hourly data was also computed.

\subsection{The System Drying Efficiency}

The system drying efficiency $\left(\eta_{d}\right)$ is the amount of heat required to evaporate the moisture inside the product and is computed from [4]. 
International Journal of Advances in Scientific Research and Engineering (ijasre), Vol 5 (10), October-2019

$\eta_{\mathrm{d}}=\frac{\text { heat output }}{\text { heat input for a given time }}$

$\eta_{d}=\frac{M L_{V}}{I_{C} A_{C} t} \times 100$

Where $\mathrm{M}$ is the amount of moisture evaporated $(\mathrm{ML})(\mathrm{Kg} / \mathrm{hr}) \mathrm{I}_{\mathrm{C}}$ is the totally hourly insulation on the collector, $\mathrm{A}_{\mathrm{c}}$ is the area of collector $\left(\mathrm{M}^{2}\right)$, $\mathrm{t}$ is the drying time, $\mathrm{L}_{\mathrm{V}}$ is the latent heat of vaporization of water $(2320 \mathrm{kj} / \mathrm{kg})$.

\section{DATA EVALUATION}

The evaluation of the solar dryer involves estimation of the following parameters

Firstly the calculation of the moisture content and also to determine the efficiency of the system

$\%$ moisture $=\frac{\mathrm{A}-\mathrm{B}}{\mathrm{A}} \times 100$

Where:

$\mathrm{A}=$ Original weight of sample

$\mathrm{B}=$ Weight of dried sample.

Evaluating the efficiency of the system can be obtained with the equation below.

$\eta_{\mathrm{d}}=\frac{\text { heat output }}{\text { heat input for a given time }}$

$\eta_{\mathrm{d}}=\frac{\mathrm{ML}}{\mathrm{I}_{\mathrm{C}} \mathrm{A}_{\mathrm{C}} \mathrm{t}} \times 100$

Where $M$ is the amount of moisture evaporated $(\mathrm{ML})(\mathrm{Kg} / \mathrm{hr}) \mathrm{I}_{\mathrm{C}}$ is the totally hourly insolation on the collector, $\mathrm{A}_{\mathrm{c}}$ is the area of collector $\left(\mathrm{M}^{2}\right)$, $\mathrm{t}$ is the drying time, $\mathrm{L}_{\mathrm{V}}$ is the latent heat of vaporization of water $(2320 \mathrm{kj} / \mathrm{kg})$.

\section{RESULTS AND DISCUSSION}

The results of the variation of solar radiation and wind speed as shown in Figure 1.1. Where the primary vertical axis shows the hourly average value of solar radiation and the secondary vertical axis shows a similar result but for wind speed. The Figure reveals that the solar radiation began to increase from 8:00 am, reaching a peak value of about $944.1\left(\mathrm{~W} / \mathrm{m}^{2}\right)$ around 2:00 pm, with a periodic rise and fall of wind speed. However the peak value was recorded around sunset further observations from the Figure shows that a decrease in solar radiation from around 4:00 pm to 6:00 pm was consistent with the increase in wind speed. This shows that there is an inverse relationship between the parameters in a particular time 


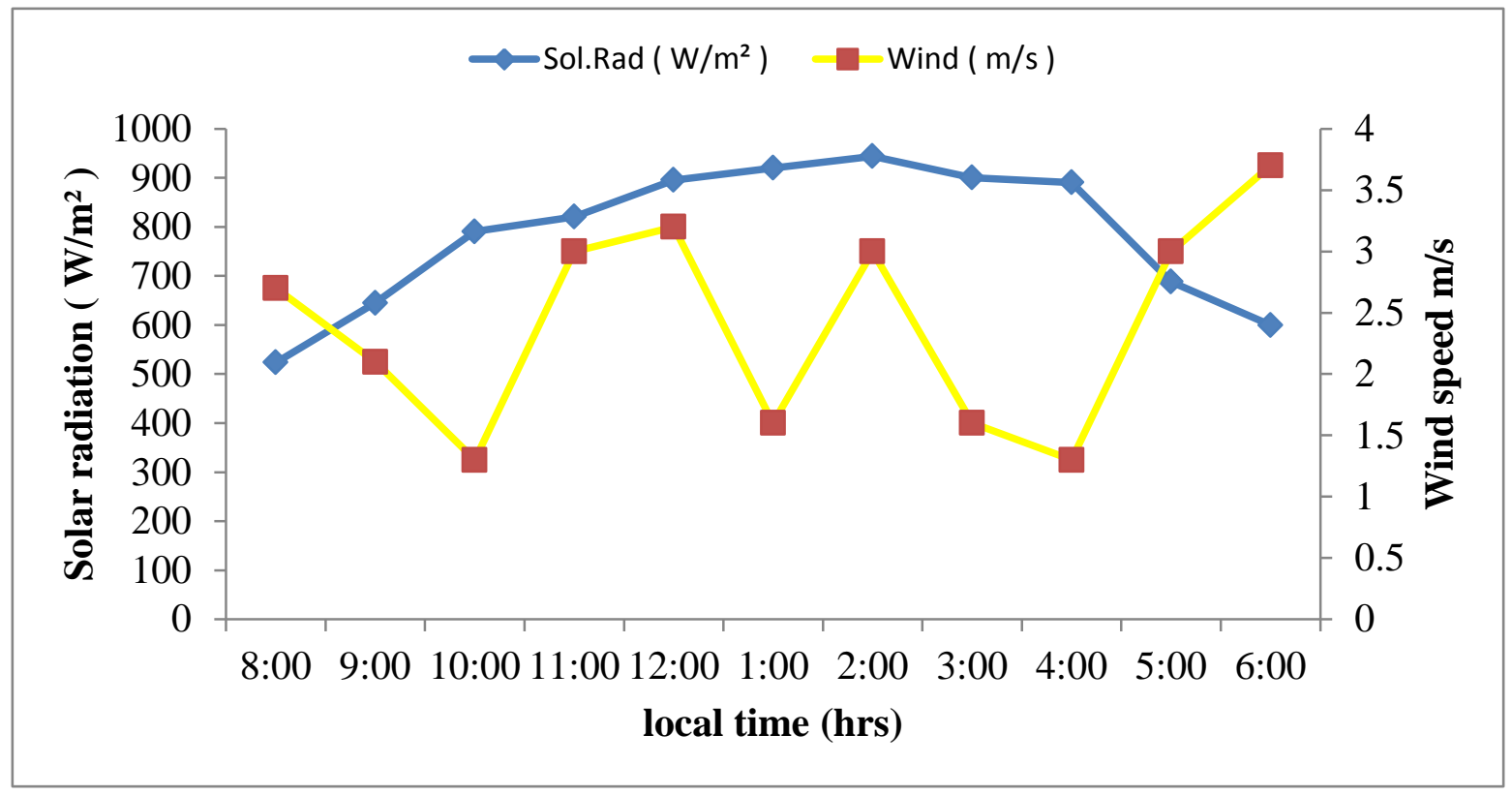

Figure 1.1 solar radiation and wind speed.

The result of the variation of wind speed and the ambient temperature as shown in Figure 1.2 Where the primary vertical axis shows the hourly average values of wind speed while the secondary vertical axis shows a similar result but for ambient temperature. The figure reveals that the wind speed shows periodic rise and fall while the ambient temperature at around 8:00 am was at its peak value of $41\left({ }^{0} \mathrm{c}\right)$ and fall. Further observation from the plot reveals that around 11:00 am to 04;00 pm the ambient temperature maintained a steady state of $40\left({ }^{0} \mathrm{c}\right)$ with still a periodic rise and fall of wind speeds at 5:00 pm the ambient temperature drop with increase in wind speed. This shows an inverse relationship of the two parameters at a certain interval.

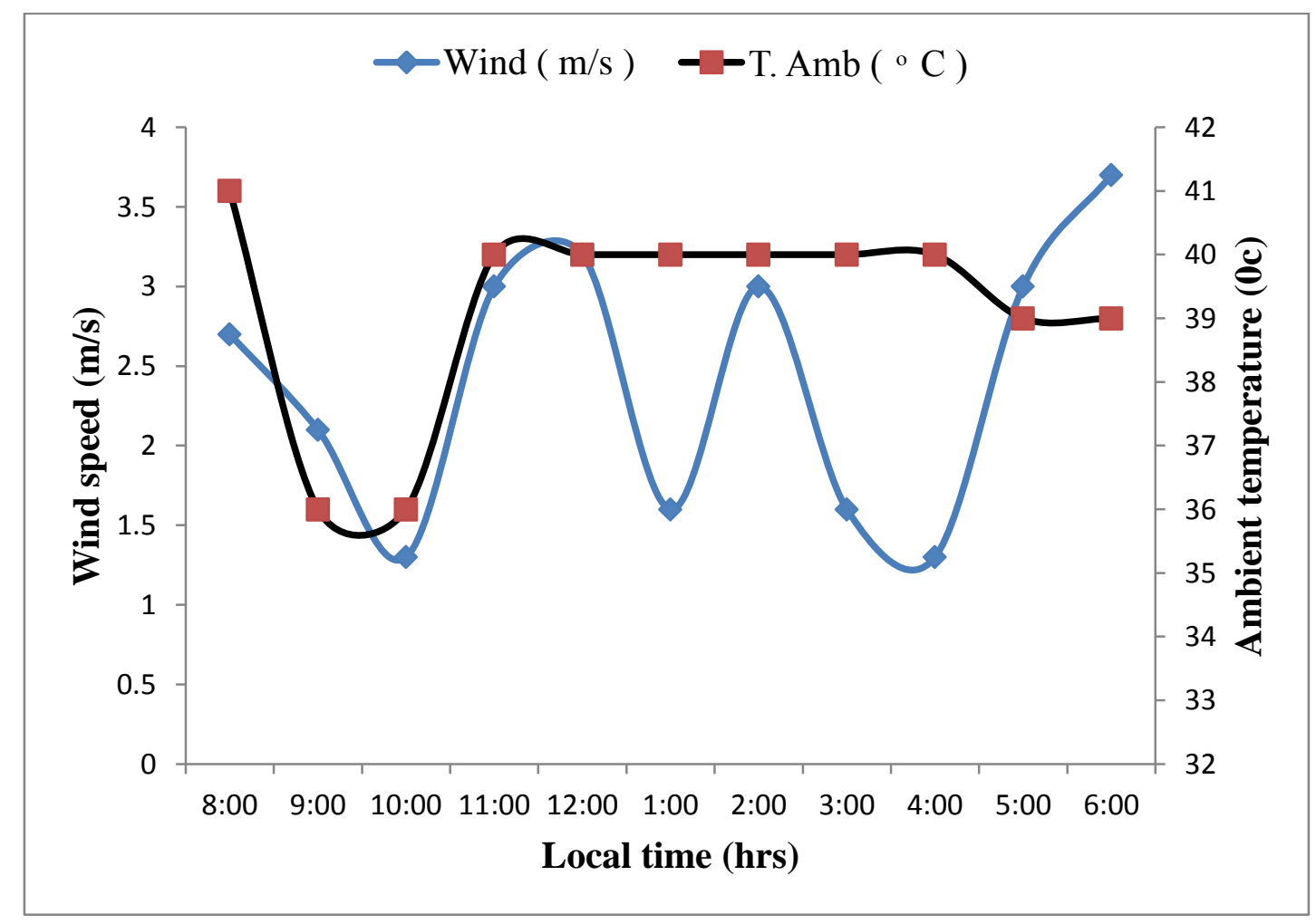

Figure 1.2 wind speed and ambient temperature 
The results of the variation of solar radiation and wind speed as shown in Figure 1.3. Where the primary vertical axis shows the hourly average value of solar radiation and the secondary vertical axis shows a similar result but for ambient temperature The Figure reveals that the solar radiation began to increase from 8:00 am, reaching a peak value of about $994.1\left(\mathrm{~W} / \mathrm{m}^{2}\right)$ around 2:00 pm while the ambient temperature at around 8:00 am was at its peak value of $41\left({ }^{\circ} \mathrm{c}\right)$ and fall. Further observation from the plot reveals that around 11:00 am to 4:00 pm the ambient temperature maintained a steady state of $40\left({ }^{0} \mathrm{c}\right)$ at around sun set both the solar radiation and the ambient temperature dropped this indicates that they have a common relationship.

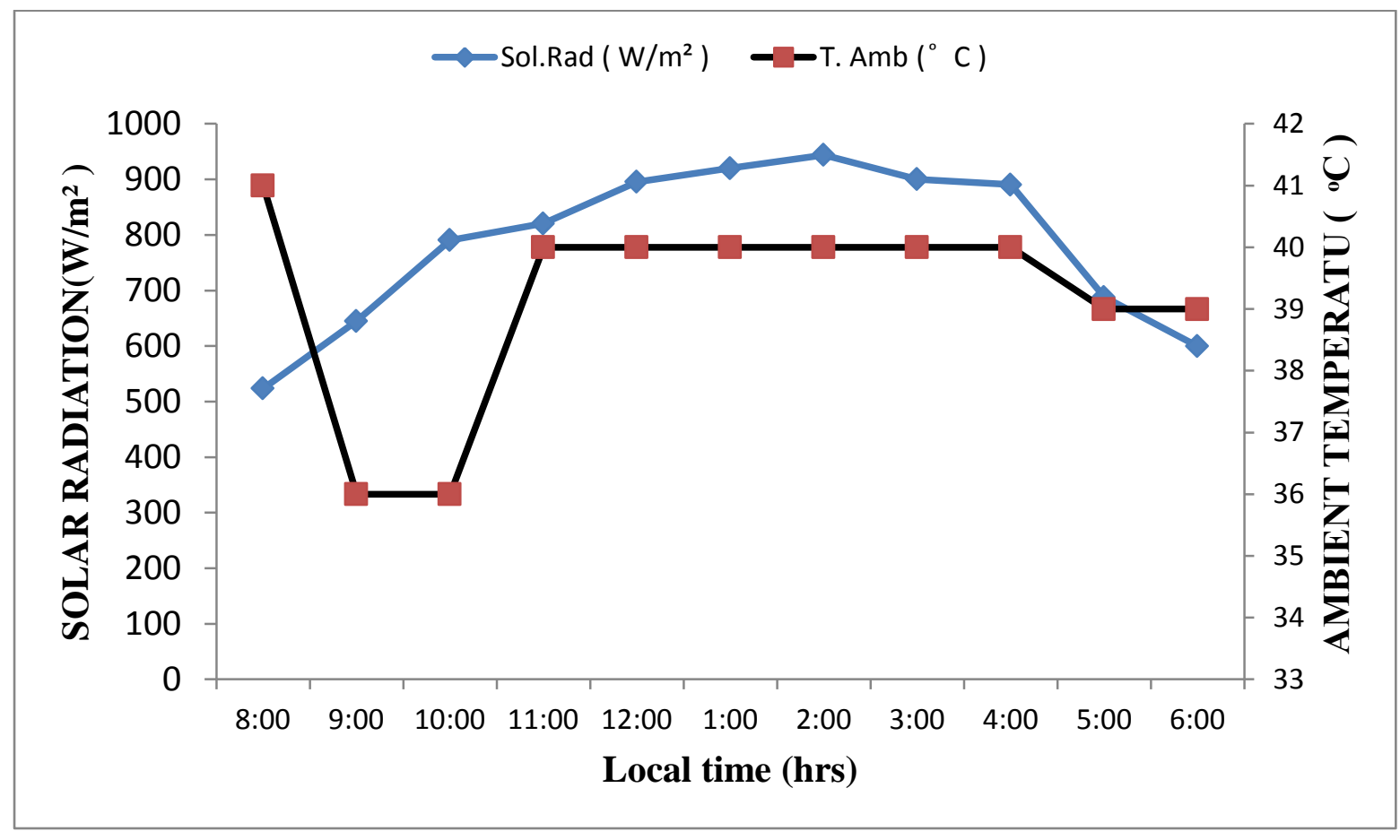

\subsection{Discussion}

Figure 1.3 solar radiation and ambient temperature

In this study solar dryer was constructed without storage. The performance of the dryer was tested based on the relationship between the solar radiation, wind speed and ambient temperature. Result from this study reveals that the solar radiation and the drying chamber temperature increased with time Figure 1.1 to 1.3 The average temperature of the drying chamber and ambient temperature of the dryer without storage was $57\left({ }^{\circ} \mathrm{c}\right)$ and $40\left({ }^{\circ} \mathrm{c}\right)$. From the result, a periodic rise and fall of wind speed and decrease in relative humidity was also noticed. However, towards sun set the wind speed decreased with increased in relative humidity because at that period there was a low solar radiation.

\section{CONCLUSION}

From the test carried out the following conclusions were made. The capital cost involved in the construction of a solar dryer with storage facilities is almost the same with the one without storage facilities and much lower to that of a mechanical dryer and also from the test carried out the simple and inexpensive of this dryer was constructed using locally sourced materials.

\section{RECOMMENDATION}

Although limitation was encountered during the execution of this research but it gives room for further research.

(1) To use aluminum sheet in constructions of solar dryer instead of galvanized sheet to compare the two materials. 
(3) More alternative material for thermal storage should be investigated to come up with one that can give the most optimal system performance.

\section{REFERENCES}

1. Orsat, V., Changrue, V., Raghavan, G.S.V., 2006, Microwave Drying of Fruits and passive solar food dryer, Leonardo Journal of Sciences, performances. Journal of Solar Energy 38(5): 311-321.

2. Liberty Jacob T (2014) design, construction and performance evaluation of a phostharvest heat

a. Storage solar energy crop dryer.( unpublished masters dissertation). University of Nigeria, Nsukka.

3. Ayooia M.A, Sunmonu, L . A, Bashiru, M .I and Jegede, O .O, Measurement net all-wave radiation at a tropical a. location ,Ile-Ife Atmosfera 27(3) ,305, 2014

4. Ezekoye and enebe, (2006) development and performance evaluation of a modified integrated passive solar grain dryer.Retrieved from https//www.researchgate.net

5. Cao G., Sofic E., Prior R.L. 1996. Antioxidant activity of tea and common vegetables. J a. Agri Food Chem 44:3426-3431drying. Journal of Solar Energy, 31(6): 605-607.

6. Velioglu YS, Mazza G, Gao L, Oomah BD .1998. Antioxidant activity and total phenolics a. in selected fruits, vegetables and grain products. J Agri Food Chem 46:4113-4117 